\title{
Alcohol exposure and outcomes in trauma patients
}

\author{
P. Hadjizacharia $\cdot$ T. O'Keeffe $\cdot$ D. S. Plurad • \\ D. J. Green · C. V. R. Brown · L. S. Chan · \\ D. Demetriades $\cdot \mathbf{P}$. Rhee
}

Received: 6 February 2010/Accepted: 13 June 2010/Published online: 22 July 2010

(c) The Author(s) 2010. This article is published with open access at Springerlink.com

\begin{abstract}
Objective To determine the injury patterns, complications, and mortality after alcohol consumption in trauma patients.

Methods The Trauma Registry at an American College of Surgeons (ACS) level I center was queried for all patients with a toxicology screen admitted between 1st January 2002 and 31st December 2005. Alcohol-positive (AP) patients were matched to control patients who had a completely negative screen (AN) using age, gender, mechanism, Injury Severity Score (ISS), head Abbreviated Injury Scale (AIS), chest AIS, abdominal AIS, and extremity AIS. Injuries and outcomes were compared between the groups.

Results As many as 5,317 patients had toxicology data, of which 471 (8.9\%) had a positive alcohol screen (AP). A total of 386 AP patients were then matched to 386 control (AN) patients. The AP group had a significantly higher mortality than the AN group overall (23 vs. 13\%;
\end{abstract}

Poster presentation at the 21st Annual Scientific Meeting of the Eastern Association for the Surgery of Trauma (EAST) at Amelia Island Plantation, Amelia Island, FL, 15-19 January 2008.

P. Hadjizacharia · T. O’Keeffe $(\bowtie) \cdot$ P. Rhee

Division of Trauma, Critical Care and Emergency Surgery, University of Arizona, 1501 N. Campbell Ave., Rm. 5411, P.O. Box 245063, Tucson, AZ 85724-5063, USA

e-mail: tokeeffe@surgery.arizona.edu

D. S. Plurad · D. J. Green · L. S. Chan · D. Demetriades Division of Trauma Surgery and Surgical Critical Care, University of Southern California, Los Angeles, CA, USA

C. V. R. Brown

Department of Surgery, University of Texas Medical Branch, Brackenridge Hospital, Austin, TX, USA $p<0.001$ ), and by ISS stratification: ISS $<16$ (6 vs. $0.4 \%$; $p<0.001)$, ISS 16-25 (53 vs. 28\%; $p=0.01)$, and ISS $>25$ (90 vs. $67 \% ; p=0.01)$. AP patients had a higher incidence of admission systolic blood pressure $<90$ (18 vs. $10 \% ; p<0.001)$ and Glasgow Coma Scale (GCS) score $\leq 8$ (25 vs. $17 \% ; p=0.002)$. AN patients had a significantly higher incidence of hemopneumothorax (11 vs. 7\%; $p=0.03)$, while AP patients had a higher incidence of cardiac arrest ( 8 vs. $3 \% ; p=0.004$ ). There was no difference in intensive care unit (ICU) and hospital length of stay.

Conclusion In a mixed population of trauma patients, an AP screen is associated with an increased incidence of admission hypotension and depressed GCS score. In this case-matched study, alcohol exposure appeared to increase mortality after injury.

Keywords Alcohol · Injury · Trauma · Complications · Mortality

\section{Introduction}

Since the first documented use of alcohol over 10,000 years ago, it has been integral to many social interactions and even asepsis and analgesia. Despite the fact that alcohol may have some health benefits in reducing heart attacks, diabetes, and even Alzheimer's, overindulgence has become a very serious problem [1-3]. In the United States, alcohol misuse is now the leading risk factor for serious injury and the third leading cause of preventable death [4].

The clinical effect of alcohol is dependent on the size, gender, and metabolic state of the individual. Due to its depressive effects on the central nervous system, initial 
effects can cause mild euphoria, relaxation, decreased inhibitions, and an impairment of judgment, as well as loss of efficiency in fine motor tasks. Later stages of intoxication can cause depressed respiration, hypotension, and even coma and death [5]. In trauma, both acute and chronic alcohol abuse is associated with a blunted physiologic response. Alcohol alters hemodynamic, metabolic, and inflammatory homeostasis after hemorrhage, blunts the catecholamine surge after injury, and reduces the electrical threshold for ventricular arrhythmias [6-8]. In the subacute phase of injury, immunosuppressive effects from alcohol increase the risk of secondary infections, caused by the attenuated neuroendocrine activation, and also by the suppression of proinflammatory cytokines [9, 10]. Cointoxication with other drugs is a common finding and it has also been shown to increase complications [11].

Numerous studies have reported an increasing risk of non-fatal and intentional injuries with increasing alcohol consumption [12-16]. In the United States, it is estimated that half a million Emergency Department (ED) visits and a third of all ED drug abuse visits yearly involve alcohol [17]. In youths aged 16-20 years, alcohol is involved in $36 \%$ of traffic-related deaths [18]. Plurad et al. [19] have shown that over $40 \%$ of trauma deaths have a positive screen for alcohol, drugs, or both. The interaction of alcohol intoxication with injury pattern and outcomes is inconsistent in the literature. In two separate studies, Plurad et al. [20] and Phelan et al. [21] showed different effects of alcohol on mortality depending on the mechanism of injury and level of intoxication, with increased complications in pedestrians, but improved survival in victims of motor vehicle crashes.

The purpose of this study was to determine the injury patterns, complications, and mortality in matched cohorts of alcohol-positive (AP) and -negative (AN) trauma patients.

\section{Methods}

Patients who were admitted between 1st January 2002 and 31st December 2005 and who underwent a toxicology screen were eligible for inclusion in our study. Patients are routinely screened for toxicology by blood and urine when admitted through the resuscitation area of our ED. Patients dying within $24 \mathrm{~h}$ of admission, patients who failed to undergo toxicology screen, and patients who were positive for multiple drugs were excluded. Our Institutional Review Board approved this study.

Data items were extracted from the trauma registry at our urban, academic American College of Surgeons (ACS)-verified level I center. The variables studied included age, gender, mechanism (blunt vs. penetrating), injury diagnoses, operative procedures, admission vitals (heart rate, systolic blood pressure), admission Glasgow Coma Scale (GCS), Abbreviated Injury Scale (AIS), Injury Severity Score (ISS), results of alcohol screen, hospital and intensive care unit length of stay, and mortality. Patients who had a positive toxicology screen for alcohol only (AP) were compared to patients who had an entirely negative screen $(\mathrm{AN})$.

Each AP patient was matched with a single AN patient on age ( $\leq 18,19-55,>55$ years), gender, mechanism of injury (blunt, penetrating), ISS $(<16,16-25,>25)$, head AIS $(<3, \geq 3)$, chest AIS $(<3, \geq 3)$, abdominal AIS $(<3$, $\geq 3$ ), and extremity AIS $(<3, \geq 3)$. Matched pairs of binary outcomes were analyzed using McNemar's test and matched pairs of continuous data were tested using the Wilcoxon signed-rank test. Differences were considered to be statistically significant at $p<0.05$. Statistical analysis was performed using the SPSS software package, version 12.0 (SPSS Inc., Chicago, IL).

\section{Results}

There were 5,317 patients studied, where 471 (8.9\%) were AP and 4,846 (91.1\%) were AN patients. We matched 386 (81.9\%) AP patients with a corresponding AN control. The matching criteria are shown in Table 1 and the admission characteristics are shown in Table 2. The AP group had a significantly greater incidence of admission hypotension (systolic blood pressure $<90 \mathrm{mmHg}$ ) and $\mathrm{GCS} \leq 8$. AN patients had a significantly higher incidence of hemopneumothorax (10.6 vs. $7.0 \%$; $p=0.03$; Table 3 ), but the injury patterns were otherwise similar. AP patients had a significantly higher incidence of in-house cardiac arrest (7.5 vs. $2.8 \% ; p=0.004)$ in comparison to AN patients, but the incidence of surgical procedures was similar (Table 4).

The comparison of admission characteristics and outcomes for the entire study populations stratified by ISS is shown in Table 5. The overall mortality in the AP group was increased (23.1 vs. $12.7 \%, p<0.001)$ compared to the AN group, which was maintained when stratified by the severity of injury. There was no difference in ICU and hospital length of stay.

\section{Discussion}

Studies have shown that 40 to $50 \%$ of trauma patients are injured while under the influence of alcohol [22-24]. An ED study reported that moderate alcohol consumption is associated with a ten-fold increased risk of injuries, and there are suggestions that this happens in a dose-dependent 
Table 1 Characteristics of the study population by matching criteria

\begin{tabular}{|c|c|c|c|}
\hline Variables & $\begin{array}{l}\text { Alcohol } \\
(n=386) \\
\%(n)\end{array}$ & $\begin{array}{l}\text { Non-intoxicated } \\
(n=386) \\
\%(n)\end{array}$ & $p$-value \\
\hline \multicolumn{4}{|l|}{ Age, years } \\
\hline$\leq 18$ & $5.4(21 / 386)$ & $5.4(21 / 386)$ & 1.00 \\
\hline $19-55$ & $82.1(317 / 386)$ & $82.1(317 / 386)$ & 1.00 \\
\hline$>55$ & $12.4(48 / 386)$ & $12.4(48 / 386)$ & 1.00 \\
\hline \multicolumn{4}{|l|}{ Gender } \\
\hline Male & $87.0(336 / 386)$ & $87.0(336 / 386)$ & 1.00 \\
\hline Female & $13.0(50 / 386)$ & $13.0(50 / 386)$ & 1.00 \\
\hline \multicolumn{4}{|c|}{ Mechanism of injury } \\
\hline Blunt & $77.7(300 / 386)$ & $77.7(300 / 386)$ & 1.00 \\
\hline Penetrating & $22.3(86 / 386)$ & $22.3(86 / 386)$ & 1.00 \\
\hline \multicolumn{4}{|l|}{ ISS } \\
\hline$\leq 15$ & $73.6(284 / 386)$ & $73.6(284 / 386)$ & 1.00 \\
\hline $16-25$ & $13.7(53 / 386)$ & $13.7(53 / 386)$ & 1.00 \\
\hline$>25$ & $12.7(49 / 386)$ & $12.7(49 / 386)$ & 1.00 \\
\hline \multicolumn{4}{|l|}{ AIS } \\
\hline \multicolumn{4}{|l|}{ Head } \\
\hline$<3$ & $83.2(321 / 386)$ & $83.2(321 / 386)$ & 1.00 \\
\hline$\geq 3$ & $16.8(65 / 386)$ & $16.8(65 / 386)$ & 1.00 \\
\hline \multicolumn{4}{|l|}{ Chest } \\
\hline$<3$ & $82.1(317 / 386)$ & $82.1(317 / 386)$ & 1.00 \\
\hline$\geq 3$ & $17.9(69 / 386)$ & $17.9(69 / 386)$ & 1.00 \\
\hline \multicolumn{4}{|l|}{ Abdomen } \\
\hline$<3$ & $92.2(356 / 386)$ & $92.2(356 / 386)$ & 1.00 \\
\hline$\geq 3$ & $7.8(30 / 386)$ & $7.8(30 / 386)$ & 1.00 \\
\hline \multicolumn{4}{|l|}{ Extremity } \\
\hline$<3$ & $93.3(360 / 386)$ & $93.3(360 / 386)$ & 1.00 \\
\hline$\geq 3$ & $6.7(26 / 386)$ & $6.7(26 / 386)$ & 1.00 \\
\hline
\end{tabular}

Equality in proportions is tested by McNemar's test; paired difference in age and ISS by Wilcoxon signed-rank test

Equality is tested by the Kappa test

fashion [14, 25]. Alcohol alters judgment, frequently leading to increasing aggression and risk-taking behavior predisposing to interpersonal violence and subsequent injury [5, 19, 22, 26-28].
The interaction of alcohol exposure and cardiovascular response to injury is variable in the literature. Experimental studies show that alcohol blunts the physiologic response to hemorrhage by inhibiting the release of vasopressin and by a depressive effect upon the myocardium [8, 29, 30]. Clinical data shows that alcohol ingestion is associated with a significantly lower systolic blood pressure on admission [31]. Alcohol intoxication can be associated with life-threatening arrhythmias, such as prolonged P-wave and QTc interval, conduction disturbances, nonspecific T-wave changes, and shortening of the action potential [32-35]. Our study supports an interaction between alcohol ingestion and cardiovascular response after injury as AP patients have a higher incidence of hypotension on presentation and cardiac arrest. AP patients may need more intensive monitoring for these cardiovascular complications.

Alcohol is a potent central nervous system depressant, reducing the level of consciousness, which can lead to stupor, coma, or even death [5, 22]. Data relating to the effects of alcohol ingestion on the GCS in trauma patients is also variable [36-38]. In a study of assault victims, there was a significant association between the degree of intoxication and the GCS [36]. In contrast, alcohol intoxication does not result in clinically significant changes in the GCS score in a study of patients with blunt traumatic brain injury [38]. Our current study concurs with this by showing that AP patients have a statistically significantly lower GCS, but with little clinical relevance, even when stratified by the severity of injury. It is apparent that alcohol can complicate the care of trauma patients, given the higher incidence of depressed mental status (GCS $\leq 8$ ), since clinicians are compelled to commit more resources to these patients.

It has been shown that alcohol exposure can be immunomodulatory. In an experimental rat study, alcohol intoxication exacerbates neutrophil apoptosis and suppresses phagocytosis in hemorrhagic shock, thus, weakening host defense to infection [9]. Our current data showed an increase in pneumonia rates between the two
Table 2 Comparison of the admission characteristics of matched groups
$S B P$ systolic blood pressure; $H R$ heart rate; GCS Glasgow Coma Scale

\begin{tabular}{lllr}
\hline Admission vitals & Alcohol $(n=386)$ & Non-intoxicated $(n=386)$ & $p$-value \\
\hline SBP & & & \\
Mean \pm SD & $111.1 \pm 53.4$ & $122.3 \pm 40.7$ & 0.01 \\
$\quad<90$ mmHG, \% $(n)$ & $18.1 \%(70 / 386)$ & $9.6 \%(37 / 386)$ & $<0.001$ \\
HR & & & 0.08 \\
Mean \pm SD & $82.5 \pm 39.6$ & $90.3 \pm 30.4$ & \\
GCS & & & $<0.001$ \\
Mean \pm SD & $11.5 \pm 4.7$ & $12.5 \pm 4.0$ & 0.002 \\
$\leq 8, \%(n)$ & $24.6 \%(95 / 386)$ & $17.1 \%(66 / 386)$ & \\
\hline
\end{tabular}


Table 3 Comparison of the injuries of matched groups

\begin{tabular}{llll}
\hline Injuries & $\begin{array}{l}\text { Alcohol } \\
(n=386) \\
\%(n)\end{array}$ & $\begin{array}{l}\text { Non-intoxicated } \\
(n=386) \\
\%(n)\end{array}$ & $p$-value \\
\hline Skull vault fracture & $3.6(14)$ & $3.4(13)$ & 1.00 \\
Basilar skull fracture & $4.9(19)$ & $4.9(19)$ & 1.00 \\
Intracranial hemorrhage & $6.2(24)$ & $8.3(32)$ & 0.20 \\
Hemopneumothorax & $7.0(27)$ & $10.6(41)$ & 0.03 \\
Lung & $7.8(30)$ & $7.0(27)$ & 0.71 \\
Cardiac & $5.4(21)$ & $5.2(20)$ & 1.00 \\
Diaphragm & $4.4(17)$ & $2.6(10)$ & 0.09 \\
Solid-organ injury & $6.2(24)$ & $5.7(22)$ & 0.85 \\
Liver & $4.9(19)$ & $3.6(14)$ & 0.38 \\
Kidney & $0.8(3)$ & $0.8(3)$ & 1.00 \\
Spleen & $1.6(6)$ & $1.8(7)$ & 1.00 \\
Hollow viscus & $4.1(16)$ & $5.7(22)$ & 0.21 \\
Stomach & $1.8(7)$ & $1.6(6)$ & 1.00 \\
Small bowel & $2.6(10)$ & $3.4(13)$ & 0.58 \\
Large bowel & $1.8(7)$ & $2.3(9)$ & 0.73 \\
Lower extremity & $5.7(22)$ & $7.3(28)$ & 0.29 \\
Femur & $2.1(8)$ & $3.6(14)$ & 0.18 \\
Tibia & $3.6(14)$ & $4.7(18)$ & 0.50 \\
Upper extremity & $5.7(22)$ & $4.1(16)$ & 0.35 \\
Humerus & $3.1(12)$ & $1.8(7)$ & 0.30 \\
Radius/ulna & $3.4(13)$ & $2.3(9)$ & 0.48 \\
Pelvic fracture & $3.6(14)$ & $4.1(16)$ & 0.82 \\
\hline & & &
\end{tabular}

Table 4 Comparison of the surgical procedures and complications of matched groups
ORIF open reduction and internal fixation

\begin{tabular}{llll}
\hline Variables & $\begin{array}{l}\text { Alcohol } \\
(n=386) \\
\%(n)\end{array}$ & $\begin{array}{l}\text { Non-intoxicated } \\
(n=386) \\
\%(n)\end{array}$ & $p$-value \\
\hline Surgical procedures & & & \\
Craniectomy & $1.6(6)$ & $2.6(10)$ & 0.42 \\
Laparotomy & $5.2(20)$ & $6.7(26)$ & 0.29 \\
Thoracotomy & $1.0(4)$ & $1.8(7)$ & 0.51 \\
ORIF & $4.1(16)$ & $3.4(13)$ & 0.63 \\
Complications & & & \\
Had a complication & $8.3(32)$ & $6.2(24)$ & 0.29 \\
Sepsis & $0.3(1)$ & $0.5(2)$ & 1.00 \\
Pneumonia & $0.8(3)$ & $3.1(12)$ & 0.02 \\
Acute respiratory failure & $0.8(3)$ & $0.3(1)$ & 0.63 \\
Acute renal failure & $0.5(2)$ & $0.3(1)$ & 1.00 \\
Cardiac arrest & $7.5(29)$ & $2.8(11)$ & 0.004 \\
\hline
\end{tabular}

groups, without effects seen on sepsis or other organ failure. Due to the small numbers of patients with complications, it is difficult to draw definitive conclusions on immunologic suppression due to alcohol ingestion in this population of trauma patients.
Data that address the interaction between alcohol use and mortality is also inconsistent but is supported by our study. Overall, the mortality was almost two-fold higher in the AP group. In an autopsy study at this institution, the authors showed that victims of penetrating trauma and 
Table 5 Comparison of the admission characteristics and outcome of matched groups stratified by Injury Severity Score (ISS)
$S B P$ systolic blood pressure; $H R$ heart rate; GCS Glasgow Coma Scale

\begin{tabular}{|c|c|c|c|}
\hline Injury Severity Score & $\begin{array}{l}\text { Alcohol } \\
(n=386) \\
\%(n)\end{array}$ & $\begin{array}{l}\text { Non-intoxicated } \\
(n=386) \\
\%(n)\end{array}$ & $p$-value \\
\hline \multicolumn{4}{|l|}{$<16$} \\
\hline $\mathrm{SBP}<90$ & $6.3(18 / 284)$ & $1.8(5 / 284)$ & 0.004 \\
\hline $\mathrm{GCS} \leq 8$ & $9.9(28 / 284)$ & $5.3(15 / 284)$ & 0.05 \\
\hline Complication & $3.2(9 / 284)$ & $0.7(2 / 284)$ & 0.07 \\
\hline Mortality & $6.0(17 / 284))$ & $0.4(1 / 284)$ & $<0.001$ \\
\hline \multicolumn{4}{|l|}{$\geq 16-25$} \\
\hline $\mathrm{SBP}<90$ & $37.7(20 / 53)$ & $18.9(10 / 53)$ & 0.03 \\
\hline $\mathrm{GCS} \leq 8$ & $49.1(26 / 53)$ & $37.7(20 / 53)$ & 0.33 \\
\hline Complication & $20.8(11 / 53)$ & $20.8(11 / 53)$ & 1.00 \\
\hline Mortality & $52.8(28 / 53)$ & $28.3(15 / 53)$ & 0.01 \\
\hline \multicolumn{4}{|l|}{$>25$} \\
\hline $\mathrm{SBP}<90$ & $65.3(32 / 49)$ & $44.9(22 / 49)$ & 0.04 \\
\hline $\mathrm{GCS} \leq 8$ & $83.75(41 / 49)$ & $63.3(31 / 49)$ & 0.02 \\
\hline Complication & $24.5(12 / 49)$ & $22.4(11 / 49)$ & 1.00 \\
\hline Mortality & $89.8(44 / 49)$ & $67.3(33 / 49)$ & 0.01 \\
\hline \multicolumn{4}{|l|}{ Total } \\
\hline $\mathrm{SBP}<90$ & $18.1(70 / 386)$ & $9.6(37 / 386)$ & $<0.001$ \\
\hline $\mathrm{GCS} \leq 8$ & $24.6(95 / 386)$ & $17.1(66 / 386)$ & 0.002 \\
\hline Complication & $8.3(32 / 386)$ & $6.2(24 / 386)$ & 0.29 \\
\hline Mortality & $23.1(89 / 386)$ & $12.7(49 / 386)$ & $<0.001$ \\
\hline
\end{tabular}

positive toxicology are more likely to have no vitals on admission in comparison to victims with negative toxicology [19]. Other studies have shown no correlation between alcohol exposure and mortality [21, 27, 30, 37, 39 ], while a number of recent reports have even suggested improved survival [20, 40-42]. The discordance between these investigations is a multifactorial issue. Study population selection bias is foremost amongst them. Data from autopsy-based, emergency room-based, and/or emergency medical services-based study populations will likely differ from hospital-based or trauma center-based studies. Results from multicenter studies [20, 21] will differ from singlecenter investigations such as the current study. Clinical data that restricts analysis to the specific mechanism of injury (penetrating only [19], pedestrians only [21] vs. motor vehicle collisions only [20]) simplifies analysis but does not facilitate the application of findings to entire populations of trauma patients. There may also be an association between injury severity and alcohol intoxication [43]. Unfortunately, like many trauma studies, particularly those examining recreational drug use, ethics preclude randomized prospective human trials. The current clinical data, however disparate, do provide valuable information that can be used to design pertinent laboratory investigations which may, in turn, lead to meaningful clinical applications.
The veracity of this report is limited by the study's retrospective design. Though most trauma patients at our institution are admitted via the resuscitation area, a number of them are not and, therefore, some patients may not receive routine drug screening. Blood alcohol levels were not consistently available; therefore, we were unable to stratify our results by the degree of intoxication. In addition, we were unable to obtain information regarding any history of chronic alcohol abuse as opposed to binge drinking. We did not include patients who died or who were discharged before $24 \mathrm{~h}$ following admission. Breaks in protocol due to various reasons common to a busy level I center can lead to further data loss. In addition, we did not include patients who were positive for multiple substances. In efforts to make the data manageable and results easily interpreted, this exclusion may have further introduced selection bias. Despite these shortcomings, we believe that this data has wide implication, supports further study on possible immunomodulatory effects of alcohol, and will be useful for preventative efforts in the community.

It will surely perpetuate the current controversies surrounding alcohol and its effect on trauma injuries and outcomes.

Although alcohol is a legal drug, it is associated with an increased risk of unfavorable results. In a mixed population of trauma patients, alcohol is associated with an increased 
incidence of hypotension and depressed GCS on admission and, further, may be associated with an increased mortality. Despite variable findings in the literature, our current data contributes greatly to the continued controversy over this issue and mandates further study.

Conflict of interest statement None.

Open Access This article is distributed under the terms of the Creative Commons Attribution Noncommercial License which permits any noncommercial use, distribution, and reproduction in any medium, provided the original author(s) and source are credited.

\section{References}

1. Zambell KL, Phelan H, Vande Stouwe C, Zhang P, Shellito JE, Molina PE. Acute alcohol intoxication during hemorrhagic shock: impact on host defense from infection. Alcohol Clin Exp Res. 2004;28:635-42.

2. Yoonhee C, Jung K, Eo E, Lee D, Kim J, Shin D, Kim S, Lee M. The relationship between alcohol consumption and injury in ED trauma patients. Am J Emerg Med. 2009;27:956-60.

3. Yaghoubian A, Kaji A, Putnam B, De Virgilio N, De Virgilio C. Elevated blood alcohol level may be protective of trauma patient mortality. Am Surg. 2009;75:950-3.

4. Tulloh BR, Collopy BT. Positive correlation between blood alcohol level and ISS in road trauma. Injury. 1994;25:539-43.

5. Taylor B, Irving HM, Kanteres F, Room R, Borges G, Cherpitel C, Greenfield T, Rehm J. The more you drink, the harder you fall: a systematic review and meta-analysis of how acute alcohol consumption and injury or collision risk increase together. Drug Alcohol Depend. 2010;110:108-16.

6. Taivainen H, Laitinen K, Tähtelä R, Kilanmaa K, Välimäki MJ. Role of plasma vasopressin in changes of water balance accompanying acute alcohol intoxication. Alcohol Clin Exp Res. 1995;19:759-62.

7. Stuke L, Diaz-Arrastia R, Gentilello LM, Shafi S. Effect of alcohol on Glasgow Coma Scale in head-injured patients. Ann Surg. 2007;245:651-5.

8. Straus SM, Kors JA, De Bruin ML, van der Hooft CS, Hofman A, Heeringa J, Deckers JW, Kingma JH, Sturkenboom MC, Stricker $\mathrm{BH}$, Witteman JC. Prolonged QTc interval and risk of sudden cardiac death in a population of older adults. J Am Coll Cardiol. 2006; 47:362-7.

9. Stein PD, Sabbah HN, Przybylski J, Goldberg DA, Hamid MS, Viano DC. Effect of alcohol upon arrhythmias following nonpenetrating cardiac impact. J Trauma. 1988;28:465-71.

10. Sperry JL, Gentilello LM, Minei JP, Diaz-Arrastia RR, Friese RS, Shafi S. Waiting for the patient to "sober up": effect of alcohol intoxication on Glasgow Coma Scale score of brain injured patients. J Trauma. 2006;61:1305-11.

11. Shih HC, Hu SC, Yang CC, Ko TJ, Wu JK, Lee CH. Alcohol intoxication increases morbidity in drivers involved in motor vehicle accidents. Am J Emerg Med. 2003;21:91-4.

12. Substance Abuse and Mental Health Services Administration (SAMHSA), Drug Abuse Warning Network (DAWN). National estimates of drug-relatedemergency department visits. Available online at: https://dawninfo.samhsa.gov/files/ED2006/DAWN 2k6ED.pdf (2006). Accessed 12 May 2010.

13. Salim A, Teixeira P, Ley EJ, DuBose J, Inaba K, Margulies DR. Serum ethanol levels: predictor of survival after severe traumatic brain injury. J Trauma. 2009;67:697-703.
14. Salim A, Ley EJ, Cryer HG, Margulies DR, Ramicone E, Tillou A. Positive serum ethanol level and mortality in moderate to severe traumatic brain injury. Arch Surg. 2009; 144:865-71.

15. Rossinen J, Sinisalo J, Partanen J, Nieminen MS, Viitasalo M. Effects of acute alcohol infusion on duration and dispersion of QT interval in male patients with coronary artery disease and in healthy controls. Clin Cardiol. 1999;22:591-4.

16. Rootman DB, Mustard R, Kalia V, Ahmed N. Increased incidence of complications in trauma patients cointoxicated with alcohol and other drugs. J Trauma. 2007;62:755-8.

17. Rivara FP, Jurkovich GJ, Gurney JG, Seguin D, Fligner CL, Ries $\mathrm{R}$, Raisys VA, Copass M. The magnitude of acute and chronic alcohol abuse in trauma patients. Arch Surg. 1993;128:907-12, discussion 912-3.

18. Conference Proceedings on Alcohol- and Drug-Related Injuries. Home page at: http://www.cdc.gov/ncipc/Spotlight/2003_Alcohol_ Conference_Proceedings.htm (2003). Accessed 12 May 2010.

19. Plurad D, Demetriades D, Gruzinski G, Preston C, Chan L, Gaspard D, Margulies D, Cryer HG. Pedestrian injuries: the association of alcohol consumption with the type and severity of injuries and outcomes. J Am Coll Surg. 2006;202:919-27.

20. Plurad D, Demetriades D, Gruzinski G, Preston C, Chan L, Gaspard D, Margulies D, Cryer G. Motor vehicle crashes: the association of alcohol consumption with the type and severity of injuries and outcomes. J Emerg Med. 2010;38:12-7.

21. Phelan H, Stahls P, Hunt J, Bagby GJ, Molina PE. Impact of alcohol intoxication on hemodynamic, metabolic, and cytokine responses to hemorrhagic shock. J Trauma. 2002;52: 675-82.

22. Mukamal KJ, Kuller LH, Fitzpatrick AL, Longstreth WT Jr, Mittleman MA, Siscovick DS. Prospective study of alcohol consumption and risk of dementia in older adults. JAMA. 2003;289:1405-13.

23. Mukamal KJ, Conigrave KM, Mittleman MA, Camargo CA Jr, Stampfer MJ, Willett WC, Rimm EB. Roles of drinking pattern and type of alcohol consumed in coronary heart disease in men. N Engl J Med. 2003;348:109-18.

24. Moore EE. Alcohol and trauma: the perfect storm. J Trauma. 2005;59:S53-6, discussion S67-75.

25. Madan AK, Yu K, Beech DJ. Alcohol and drug use in victims of life-threatening trauma. J Trauma. 1999;47:568-71.

26. Lorsheyd A, de Lange DW, Hijmering ML, Cramer MJ, van de Wiel A. PR and OTc interval prolongation on the electrocardiogram after binge drinking in healthy individuals. Neth $\mathrm{J}$ Med. 2005;63:59-63.

27. Li G, Chanmugam A, Rothman R, DiScala C, Paidas CN, Kelen GD. Alcohol and other psychoactive drugs in trauma patients aged 10-14 years. Inj Prev. 1999;5:94-7.

28. Koppes LL, Dekker JM, Hendriks HF, Bouter LM, Heine RJ. Moderate alcohol consumption lowers the risk of type 2 diabetes: a meta-analysis of prospective observational studies. Diabetes Care. 2005;28:719-25.

29. Horton JW. Cardiac contractile effects of ethanolism and hemorrhagic shock. Am J Physiol. 1992;262:H1096-103.

30. National Institutes of Health Fact Sheet. Alcohol-related traffic deaths. Available online at: http://www.nih.gov/about/ researchresultsforthepublic/AlcoholRelatedTrafficDeaths.pdf (2007). Accessed 2 May 2010.

31. National Institute on Alcohol Abuse and Alcoholism (NIAAA) of the National Institutes of Health. Home page at: http://www. niaaa.nih.gov/. Accessed 12 May 2010.

32. Greiffenstein P, Mathis KW, Stouwe CV, Molina PE. Alcohol binge before trauma/hemorrhage impairs integrity of host defense mechanisms during recovery. Alcohol Clin Exp Res. 2007;31:704-15. 
33. Dunn CW, Donovan DM, Gentilello LM. Practical guidelines for performing alcohol interventions in trauma centers. J Trauma. 1997;42:299-304.

34. Demetriades D, Gkiokas G, Velmahos GC, Brown C, Murray J, Noguchi T. Alcohol and illicit drugs in traumatic deaths: prevalence and association with type and severity of injuries. J Am Coll Surg. 2004;199:687-92.

35. Cornwell EE 3rd, Belzberg H, Velmahos G, Chan LS, Demetriades D, Stewart BM, Oder DB, Kahaku D, Chan D, Asensio JA, Berne TV. The prevalence and effect of alcohol and drug abuse on cohort-matched critically injured patients. Am Surg. 1998;64:461-5.

36. Cherpitel CJ, Ye Y, Bond J. Alcohol and injury: multi-level analysis from the emergency room collaborative alcohol analysis project (ERCAAP). Alcohol Alcohol. 2004;39:552-8.

37. Chen SC, Lin FY, Chang KJ. Body region prevalence of injury in alcohol- and non-alcohol-related traffic injuries. J Trauma. 1999;47:881-4.

38. Brickley MR, Shepherd JP. The relationship between alcohol intoxication, injury severity and Glasgow Coma Score in assault patients. Injury. 1995;26:311-4.
39. Brackett DJ, Gauvin DV, Lerner MR, Holloway FA, Wilson MF. Dose- and time-dependent cardiovascular responses induced by ethanol. J Pharmacol Exp Ther. 1994;268:78-84.

40. Borges G, Cherpitel CJ, Orozco R, Bond J, Ye Y, Macdonald S, Giesbrecht N, Stockwell T, Cremonte M, Moskalewicz J, Swiatkiewicz G, Poznyak V. Acute alcohol use and the risk of non-fatal injury in sixteen countries. Addiction. 2006; 101:993-1002.

41. Borges G, Cherpitel CJ, Mondragón L, Poznyak V, Peden M, Gutierrez I. Episodic alcohol use and risk of nonfatal injury. Am J Epidemiol. 2004;159:565-71.

42. Borges G, Cherpitel C, Orozco R, Bond J, Ye Y, Macdonald S, Rehm J, Poznyak V. Multicentre study of acute alcohol use and non-fatal injuries: data from the WHO collaborative study on alcohol and injuries. Bull World Health Organ. 2006;84:453-60.

43. Aaseb $\varnothing$ W, Erikssen J, Jonsbu J, Stavem K. ECG changes in patients with acute ethanol intoxication. Scand Cardiovasc J. 2007;41:79-84. 